\title{
Importance of Q fever in community acquired pneumonia
}

\author{
MONiQue Goyette mD, JeAn Bouchard mD, ANDré Poirier mD mSc, ERIC MORRIER BSc, \\ HARVEY ARTSOB PhD, FRANCOIS CORBEIL MD
}

\begin{abstract}
M GOYETTE, J BOUCHARD, A POIRIER, E MORRIER, H ARTSOB, F CORBEIL. Importance of Q fever in community acquired pneumonia. Can J Infect Dis 1996;7(6):370-373. Coxiella burnetii appears to be endemic in animals in the Mauricie region of Quebec, and causes some human cases of $Q$ fever annually. Unlike in other rural areas, patients in this study experienced few respiratory symptoms. To determine whether $C$ burnetii pneumonia is underdiagnosed, adults admitted to hospital for community acquired pneumonia were included in a one-year serological study. Significant immunofluorescent antibody (IFA) titres in four of 118 patients with pneumonia (fewer than $4 \%$ ) were studied. Clinical presentation, standard laboratory tests and epidemiological data did not allow identification of these cases; however, $\mathrm{Q}$ fever increased during the warm months. There were no detectable complement fixing (CF) antibodies in these four cases. $C$ burnetii causes few cases of pneumonia in Mauricie. IFA seems to be a more sensitive test than CF.
\end{abstract}

Key Words: Coxiella burnetii, Pneumonia, Q Fever

\section{L'importance de la fièvre $Q$ lors de pneumonie acquise en communauté}

RÉSUMÉ : Coxiella burnetii paraît endémique chez les animaux de la Mauricie au Québec, causant annuellement plusieurs cas humains de Fièvre $Q$. Contrairement à ce qui a été observé dans d'autres régions rurales, nos patients ont présenté peu de symptômes respiratoires. Afin de s'assurer qu'il n’y avait pas de sous-détection des pneumonies à C burnetii, les adultes admis à l'hôpital pour une pneumonie acquise en communauté ont été enrolés dans une étude sérologique d'une durée d'un an. Des titres significatifs en immunofluorescence indirecte (IFA) lors de 4/118 pneumonies (moins de 4\%) ont été observés. Les tableaux cliniques, les analyses de laboratoire de base et les données épidémiologiques n'avaient pas permis de suspecter les cas; cependant l'incidence était supérieure durant la saison chaude. Il n'y avait pas d'anticorps détectables en fixation du complément (CF) pour ces 4 cas. $C$ burnetii cause peu de pneumonies ainsi que pour 41 autres patients testés. En conclusion, C burnetii cause peu de pneumonies en Mauricie. L'IFA apparait comme un test plus sensible que la CF.

Q fever was recently identified as an endemic zoonosis in Mauricie, a partially rural area in the central part of Quebec, located near the Eastern Townships. The first Canadian cases of $Q$ fever were reported in this area at the end of the 1950s. A regional study conducted in 1992 and 1993 showed an animal seroprevalence for Coxiella burnetii of $28 \%$
(82 of 297) in cats and 12\% (12 of 104) in cattle (unpublished data). Nine human cases were diagnosed during an 18-month period, and a $20 \%$ human seroprevalence in a local slaughterhouse was documented (2). Clinical cases were primarily middle-aged men who reported an abrupt onset of a high fever, severe headache, fatigue and myalgia. None of the patients

Centre Hospitalier St-Joseph, Trois-Rivières, Québec and National Laboratory for Special Pathogens, Laboratory Centre for Disease Control, Ottawa, Ontario

Correspondence and reprints: Dr Monique Goyette, chef du service de microbiologie et maladie infectieuses, Centre Hospitalier St-Joseph, 731, Ste-Julie Trois-Rivières, Québec G9A 1Y1. Telephone 819-379-8112, fax 819-379-0918

Received for publication December 20, 1995. Accepted May 20, 1996 
TABLE 1

Epidemiological data and serological results for patients with Coxiella burnetii pneumonia

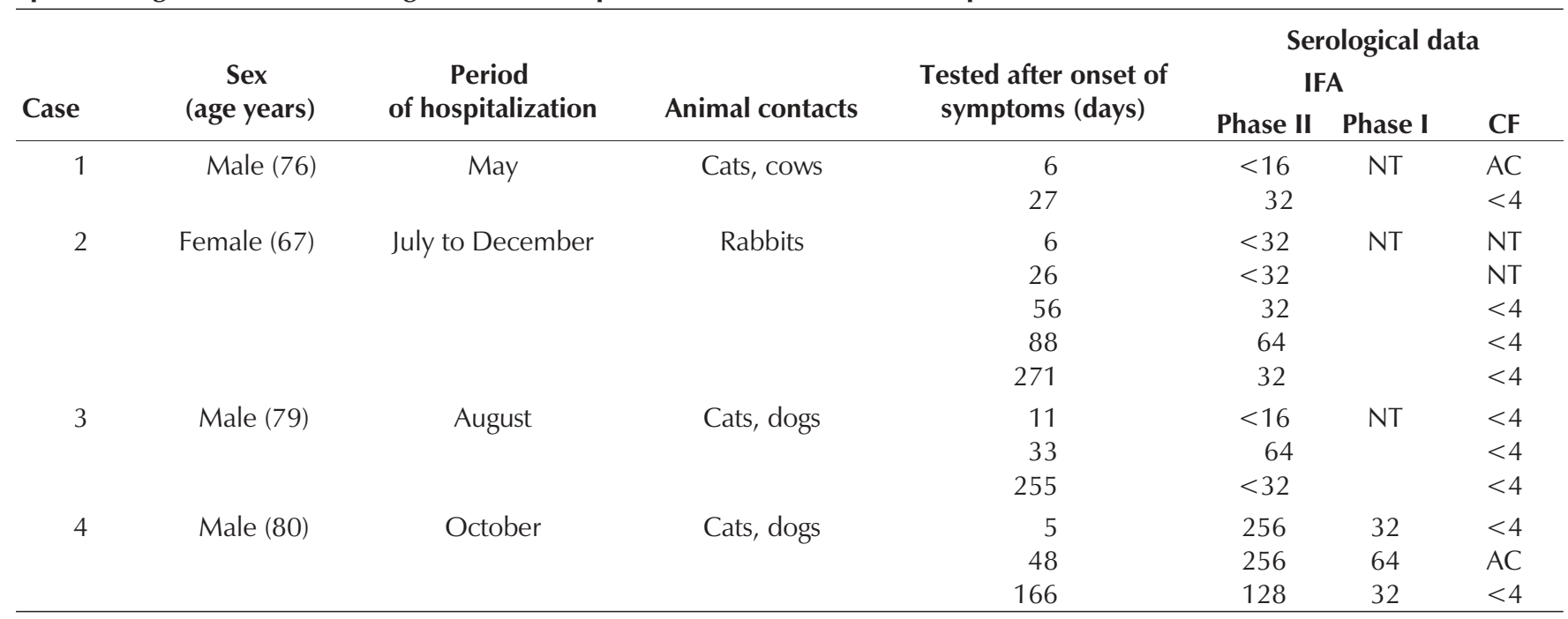

AC Anticomplementary reaction; CF Complement fixation test; IFA Immunofluorescent antibody test; NT Not tested

had clinical or radiological evidence of pneumonia; this finding was remarkable because $\mathcal{Q}$ fever is known to cause an atypical pneumonia (3-13). For example, in 10 rural Nova Scotia hospitals, C burnetii was responsible for $21.8 \%$ of community acquired pneumonia in 1983 (3). Q fever may be underdiagnosed because clinical symptoms, x-rays and standard laboratory tests are often nonspecific (13). Complement fixation (CF) serology can miss $20 \%$ to $46 \%$ of cases $(3,14)$. Q fever is important because the infection does not respond to beta-lactams or erythromycin, and there is a risk of reactivation in the future. To understand the role of $Q$ fever in adults hospitalized for community acquired pneumonia in Mauricie, a one-year serological study was conducted.

\section{PATIENTS AND METHODS}

The Centre Hospitalier St-Joseph is a 300-bed, adult hospital in Trois-Rivières, a city with a population of 50,000, located in a partly rural area north-east of Montreal (regional population of 450,000 ). It is a reference centre for care in respirology and infectious diseases with four respirologists and three infectious disease specialists on staff. Between November 1992 and November 1993, the hospital admission list was reviewed daily to identify patients admitted with suspected pneumonia. Inclusion criteria were three or more clinical symptoms including sputum, chest pain, fever, dyspnea, changes in consciousness, abnormal lung auscultation and leukocytosis, and chest $\mathrm{x}$-ray compatible with pneumonia.

Of 184 patients with an initial diagnosis of pneumonia, 66 were excluded because of unconfirmed diagnosis (39), rapid discharge (six), refusal or inability to consent (six), rapid death (five) or nosocomial complications (12 patients transferred from other centres).

The remaining 118 patients were enrolled in the study after providing written consent. They answered a brief epidemiological questionnaire concerning contact with animals during the previous month, occupation and home location. One serological sample was drawn at enrollment and a second one after a minimum three-week interval. Analysis was done at Laboratory Centre for Disease Control in Ottawa. Two assay methods were used for the first 41 patients; subsequently, CF was used only on samples that tested positive in the immunofluorescent antibody (IFA) test.

IFA test: Coxiella burnetii phase II antigen prepared from the Nine Mile strain was purchased from Centers for Disease Control and Prevention (CDC, Atlanta, Georgia), and antigencoated wells were prepared as recommended by CDC. Sera to be tested were diluted in phosphate buffered saline (PBS) containing $3 \%$ normal yolk sac. Sera were tested at screening dilutions of 1:32 because fluorescence is less specific under this dilution for most Rickettsiae. Positive sera were retested at initial dilutions of 1:16, using phase I antigen. Test sera were added to antigen-coated wells and incubated in a moist chamber at $37^{\circ} \mathrm{C}$ for 35 mins. Slides were washed twice with PBS and then air dried. A fluorescent isothiocyanin-labelled goat antihuman conjugate purchased from Sigma Chemical Company (Missouri) diluted in PBS containing a 1:400 dilution of Evan's Blue was added to each well, and the slides were incubated in a moist chamber at $37^{\circ} \mathrm{C}$ for 35 mins. The slides were washed twice with PBS, air dried, mounted using phosphate-buffered glycerol and then examined by ultraviolet microscopy at a magnification of 400 .

CF test: CF tests were conducted by a modification of the microtitre method described by Sever (15). Two units of antisheep hemolysin, two units of complement and four units of antigen were used in the test. The sheep cell concentration was reduced to $0.4 \%$ for greater sensitivity. Initial dilutions of sera tested were 1:8. $Q$ fever phase II antigen used was purchased from Instituto Immunlogico Italiano (ISMUNIT), Rome, Italy.

The criteria for a positive serological diagnosis was a fourfold rise in antibody titre or, if only a convalescent serum was available a titre of 256 or greater by IFA, or 64 or greater by 
CF. Phase II:phase I ratio is generally greater than one in acute cases and one or less in chronic cases. Immunoglobulin (Ig) M was not consistently tested, but was completed in two ambiguous cases.

\section{RESULTS}

Of the 118 patients enrolled, nine did not complete the study: five died before the second serum sample could be taken, and four were noncompliant. Of the 109 remaining patients, 104 were negative for $C$ burnetii serology. Four patients had positive serological results (Table 1); a fifth patient had a nondiagnostic reaction.

The first patient, a cat owner, often walked near dairy farms. He was admitted with bacteremic pneumococcal pneumonia and initially responded to treatment with penicillin. Six days later, fever and cough recurred, and he did not respond to 10 days of cefadroxyl treatment. Finally, the fever subsided with ciprofloxacin therapy, and the infiltrate regressed very slowly. Some anticomplementary reaction was initially present in this patient's serum.

The second patient was in contact with her grandchildren's young rabbits; she was hospitalized four times over a fivemonth period for pneumonia. Pseudomonas aeruginosa was identified in her sputum cultures during her first two hospitalizations. She received different antibiotics, some of which were quinolones. Bronchiectasis was not present and the cause of her repeated pneumonias was not apparent.

The third patient had an abrupt onset of fever, headache and liver tenderness, followed by severe pneumonia six days later. There was no clinical response to ceftriaxone and erythromycin. Aspiration pneumonia was then suspected. Subsequently he received clindamycin and recovered a few days later.

Five days after the onset of symptoms, the fourth patient had a high phase II titre by IFA, a high phase II:I ratio of 8 and later an anticomplementary reaction. However, IgM was not detectable. No febrile episodes had been reported within the past three years, and the patient remained in good health in the following year.

The fifth patient, who had occasional contact with a dog, was admitted with bacteremic pneumococcal pneumonia which responded to penicillin. He had an IFA titre of less than 32 on the first serum, and a low titre (32) in the second sample drawn five weeks later. CF was negative and IgM antibodies were negative by IFA. This was considered to be the consequence of a previous infection.

The four cases were similar to the 105 controls in sex (male $75 \%$ versus $51 \%$ ), age (75 years versus 66 ), employment rate ( $0 \%$ versus $14 \%$ ), animal contacts ( $100 \%$ versus $70 \%$ ) and home location. The four cases occurred between May and October (four of 53 pneumonia during these months), but none occurred between November and April.

\section{DISCUSSION}

Ninety-two per cent of enrolled patients completed the study. There was an average of 27 days between the taking of the two serological samples. $C$ burnetii does not appear to be an important cause of community acquired pneumonia in this area. The rate (less than $4 \%$ ) is much lower than the $21.8 \%$ observed in rural Nova Scotia 11 years ago (3).

Our patients were relatively old, often retired and likely exposed to a smaller inoculum than subjects with occupational acquisition. The results did not provide a populationbased estimate of the incidence of $C$ burnetii pneumonia, but documented the limited importance of this microorganism in the illnesses of adults sufficiently ill to require hospitalization. Other cases that were clinically mild likely occurred in this area during the study period, but remained undetected.

The literature suggests that the clinical manifestations of $Q$ fever vary with age $(3,5,16-18)$, strain of organism $(13,19,21)$, presence of immunosuppression (20-23), density of inoculum $(4,5)$ and route of infection $(12,24)$. Our previously reported human cases (2) were similar to those reported in Ontario (25), with a febrile syndrome and abnormal liver tests, but rarely manifesting respiratory symptoms.

From these observations, neither clinical manifestations nor standard laboratory tests were useful in identifying cases. Similar observations were reported in Nova Scotia where C burnetii pneumonia was correctly suspected in only $33 \%$ of patients, even when patients presented more typically with fever, chills, severe headache, anorexia and a nonproductive cough (13). The literature suggests that approximately $45 \%$ of patients do not present with respiratory symptoms $(4,11)$. The clinical presentations of our patients varied, perhaps due to well known complications that occur in elderly patients, and included secondary infection (12\%), congestive heart failure $(11 \%)$, gastrointestinal hemorrhage $(3 \%)$, respiratory failure (3\%) and renal failure (2\%) (27). Severity of infection is generally moderate but about $25 \%$ of admitted patients have rapidly progressive pneumonia (13) and death may occur (12).

Epidemiological observations collected here were not useful, except perhaps the observation that greater incidence of disease was seen during the warm months. Tracking of animal contact was unhelpful; in rural areas animal contacts are frequent. In Spain, seasonal variation was related to the reproductive cycle of domestic animals, with most infections occuring in young men $(10,11)$. Laboratory observations were also unhelpful. Half of the patients had mild elevation of transaminases. In addition sedimentation rate was often elevated, but white blood cell counts remained normal $(11,13)$. Radiographical findings also vary, although some authors have reported round pulmonary opacities (4), subsegmental and segmental pleural-based alveolar opacities (13) and slow clearing infiltrates (26), suggesting the presence of $C$ burnetti.

Due to the lack of specific clinical or laboratory findings, underdiagnosis of $C$ burnetti pneumonia is likely.

Serological cross-reactions that would explain a false C burnetii antibody increase during bacterial or rickettsial infections are not described in the literature $(14,27,28,33)$. Although CF testing is believed to be quite specific, it is generally conceded to be less sensitive and more labour intensive than IFA $(3,14,20)$. Anticomplementary activity of serum is frequently present in $\mathcal{Q}$ fever, which poses a diagnostic problem $(4,14,29)$. Antibodies are detected earlier by IFA and 
seroconversion may be missed, (3) so specific IgM serology could theoretically aid the diagnosis of acute infection. However, IgM antibodies are often detected more than six months after an acute infection $(30,31)$, as well as during the chronic infection phase $(32,33)$. The sensitivity of IgM antibodies is also poor (14), and the test is not currently available to clinicians. The fourth case, who did not remember any febrile episode in the three years before admission to hospital and stayed in good health the following year, was considered an acute case, but a recrudescence could not be excluded.

This study does not suggest that $C$ burnetii is a frequent cause of pneumonia in our geographic area. Therefore, routine

\section{REFERENCES}

1. Vallières A, Goyette $M$, Bigras-Poulin $M$, et al. Séroprévalence de Coxiella burnetii au sein d'une population de chats domestiques au Québec. Bulletin de l'Association pour l'étude de l'épidémiologie des maladies animales. Epidemiol Sante Anim 1996;29:43-9.

2. Goyette M, Poirier A, Bouchard J, Morrier E. Q fever in Quebec (1989-93): Report of 14 cases. Can J Infect Dis 1994;5:113-8.

3. Marrie TJ, Haldane EV, Faulkner RS, Kwan C, Grant B, Cook F. The importance of Coxiella burnetii as a cause of pneumonia in Nova Scotia. Can J Public Health 1985;76:233-6.

4. Langley JM, Marrie TJ, Covert A, Waag DM, Williams JC. Poker players' pneumonia. N Engl J Med 1988;319:354-6.

5. Dupuis G, Péter O, Pedroni D, Petite J. Aspects cliniques observés lors d'une Epidémie de 415 cas de Fièvre Q. Schweiz Med Woechenschr 1985;115:814-8.

6. Connolly JH, Coyle PV, Adgey AAJ, O'Neill HJ, Simpson DM. Clinical Q fever in Northern Ireland 1962-1989. Ulster Med J 1990;59:137-44.

7. Salmon MM, Howells B. O fever in an urban area. Lancet $1982 ; \mathrm{i}: 1002-4$

8. Reilly S, Northwood JL, Caul EO. Q fever in Plymouth, 1972-88. Epidemiol Infect 1990;105:391-408.

9. Winner SJ, Eglin RP, Moore VIM, Mayon-White RT. An outbreak of $Q$ fever affecting postal workers in Oxfordshire. J Infect $1987 ; 14: 255-61$.

10. Tellez A, Perez-Brena P, Fernandez-Patino MV, Leon P, Anda P, Najera R. Acute respiratory disease in Spain; seven years of experience. Rev Infect Dis 1990;12:745-53.

11. Sobradillo V, Ansola P, Baranda F, Corral C. Q fever pneumonia: A review of 164 community-acquired cases in the Basque country. Eur Respir J 1989;2:263-6.

12. Dupont HT, Raoult D, Brouqui P, et al. Epidemiologic features and clinical presentation of acute $Q$ fever in hospitalized patients: 323 French cases. Am J Med 1992;93:427-34.

13. Marrie TJ. Q fever pneumonia. Semin Respir Infect 1989;4:47-55.

14. Péter O, Dupuis G, Burgdorfer W, Peacock M. Evaluation of the complement fixation and indirect immunofluorescence tests in the early diagnosis of primary $Q$ fever. Eur J Clin Microbiol 1985;4:394-6.

15. Sever JL. Application of a microtechnique to viral serological investigations. J Immunol 1962;77:320-29.

16. Pinsky RL, Fishbein DB, Green CR, Gensheimer KF. An outbreak of cat-associated Q fever in the United States. J Infect Dis 1991;164:202-4. serological testing for this agent is not recommended. Further studies are required to determine the exact role of $C$ burnetii in the pathogenesis of pneumonia in the elderly. In the near future it is hoped that there will be more information about the incidence and clinical manifestations of $\mathcal{Q}$ fever in Canada.

ACKNOWLEDGEMENTS: The authors thank Dr Thomas Marrie, Dalhousie University, Halifax, Nova Scotia; Centre Hospitalier St-Joseph colleagues; Dr Maxwell Garvie, Laboratory Centre for Disease Control, Ottawa, Ontario; Dr Peter Kogon, Quebec University, Trois Rivières, Quebec; and Richard Leblanc for manuscript editing.

17. Richardus JH, Dumas AM, Huisman J, Schaap JP. Q fever in infancy: A review of 18 cases. Pediatr Infect Dis 1985;4:369-73.

18. Ruiz-Contreras J, Montero RG, Amador JTR, Corradi EG, Vera AS. Q fever in children. Am J Dis Child 1993;147:300-2.

19. Marrie TJ. A comparison of $Q$ fever endocarditis with native valve endocarditis. Ann NY Acad Sci 1990;590:61-7.

20. Raoult D, Marrie T. Q fever. Clin Infect Dis 1995;20:489-96.

21. Raoult D, Brouqui P, Marchou B, Gastaut JA. Acute and chronic Q fever in patients with cancer. Clin Infect Dis 1992;14:127-30.

22. Kanfer E, Farrag N, Price C, MacDonald D, Coleman J, Barrett AJ. Q fever following bone marrow transplantation. Bone Marrow Transplant 1988;3:165-6.

23. Heard SR, Ronalds CJ, Heath RB. Coxiella burnetii infection in immunocompromised patients. J Infect 1985;11:15-8.

24. Marrie T, Stein A, Janigan D, Raoult D. The route of infection determines the clinical manifestations of acute $Q$ fever. Interscience Conference on Antimicrobial Agents and Chemotherapy. San Francisco, September 17-20, 1995. (Poster)

25. Vellend H, Salit IE, Spence L, et al. Q fever - Ontario. Can Dis Wkly Rep 1982;8:171-2.

26. Smith DL, Wellings R, Walker C, Ayres JG, Burge PS. The chest $\mathrm{X}$-ray in $\mathrm{Q}$ fever; A report on 69 cases from the 1989 West Midlands outbreak. Br J Radiol 1991;64:1101-8.

27. Marrie TJ, Durant H, Yates L. Community-acquired pneumonia requiring hospitalization: 5-year prospective study. Rev Infect Dis 1989;11:586-99.

28. Olson JG, McDade JE. Rickettsia and Coxiella. In: Murray PR, ed. Manual of Clinical Microbiology, 6th edn. Washington: American Society for Microbiology, 1995:678-85.

29. Walker DH, Peacock MG. Laboratory Diagnosis of Rickettsial Diseases, vol 2. Boca Raton: CRC Press Inc, 1988:145.

30. Guigno D, Coupland B, Smith EG, Farrel ID, Desselberger U, Caul EO. Primary humoral antibody response to Coxiella burnetii, the causative agent of $\mathrm{Q}$ fever. J Clin Microbiol 1992;30:1958-67.

31. Uhaa IJ, Fishbein DB, Olson JG, Rives CC, Waag DM, Williams JC Evaluation of specificity of indirect enzyme-linked immunosorbent assay for diagnostic of human Q fever. J Clin Microbiol 1994;32:1560-5.

32. Peacock MG, Philip RN, Williams JC, Faulkner RS. Serological evaluation of $Q$ fever in humans: Enhanced phase I titers of immunoglobulins $\mathrm{G}$ and $\mathrm{A}$ are diagnostic for $\mathrm{Q}$ fever endocarditis. Infect Immun 1983;41:1089-98.

33. Hunt JG, Field PR, Murphy AM. Immunoglobulin responses to Coxiella burnetii ( $Q$ fever); Single-serum diagnosis of acute infection using an immunofluorescence technique. Infect Immun 1983;39:977-81. 


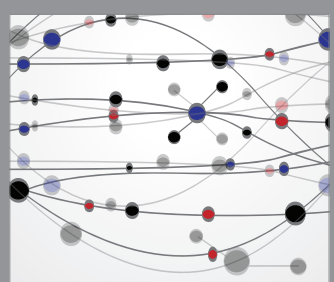

The Scientific World Journal
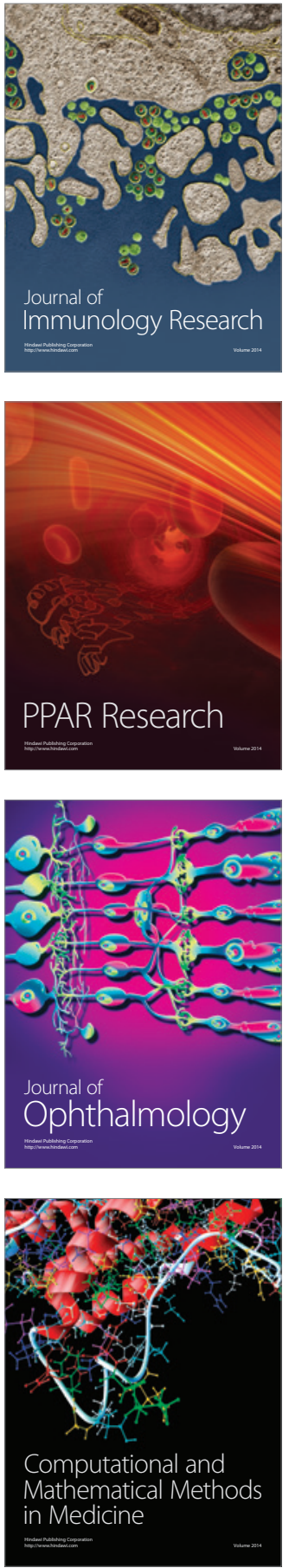

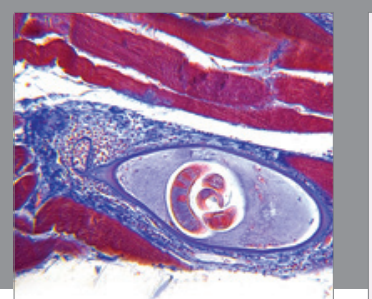

Gastroenterology Research and Practice

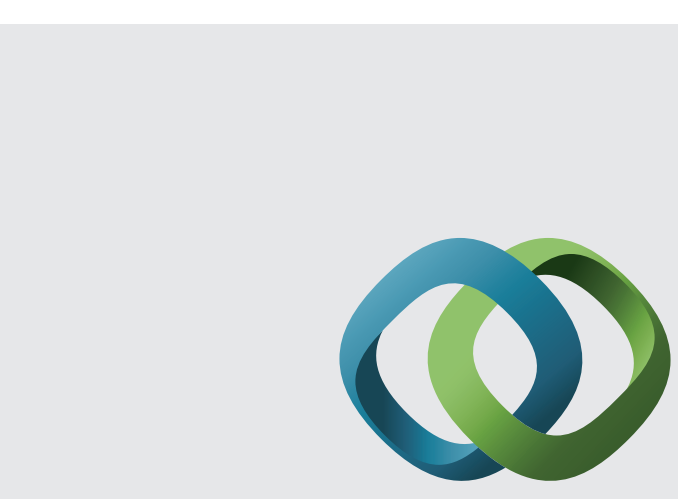

\section{Hindawi}

Submit your manuscripts at

http://www.hindawi.com
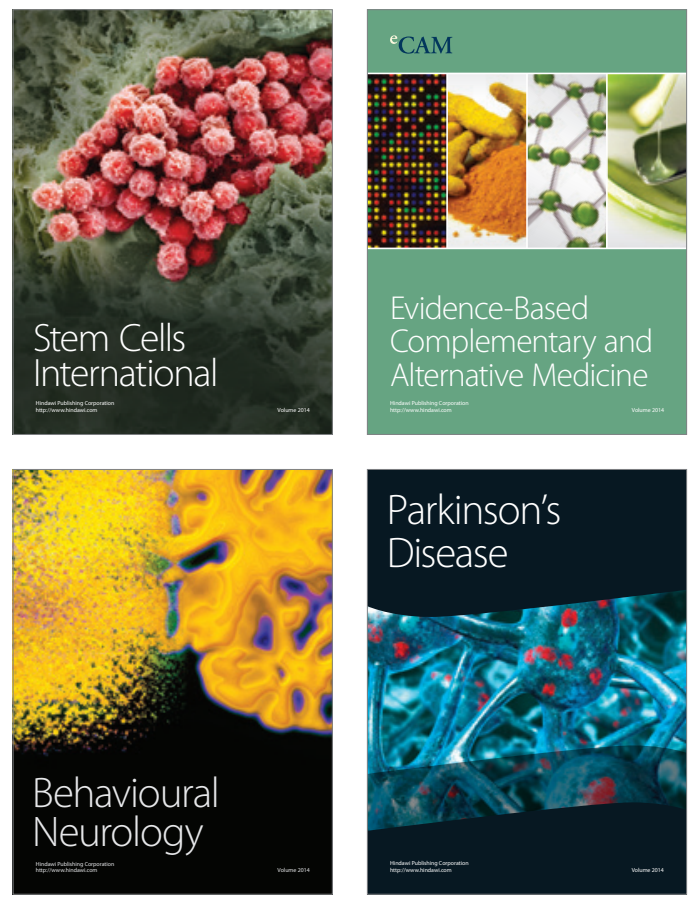
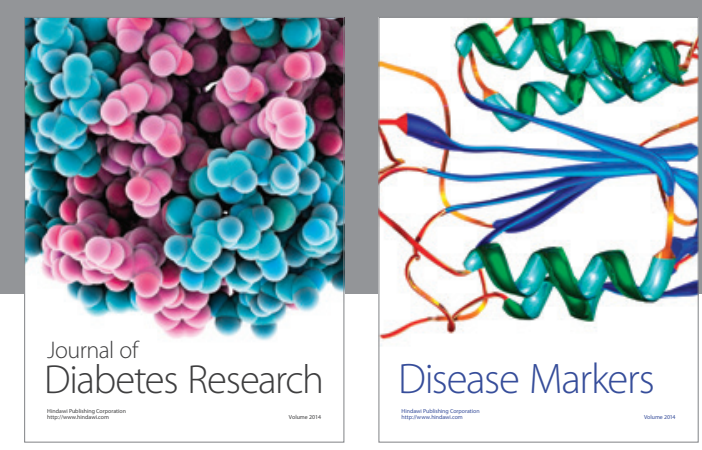

Disease Markers
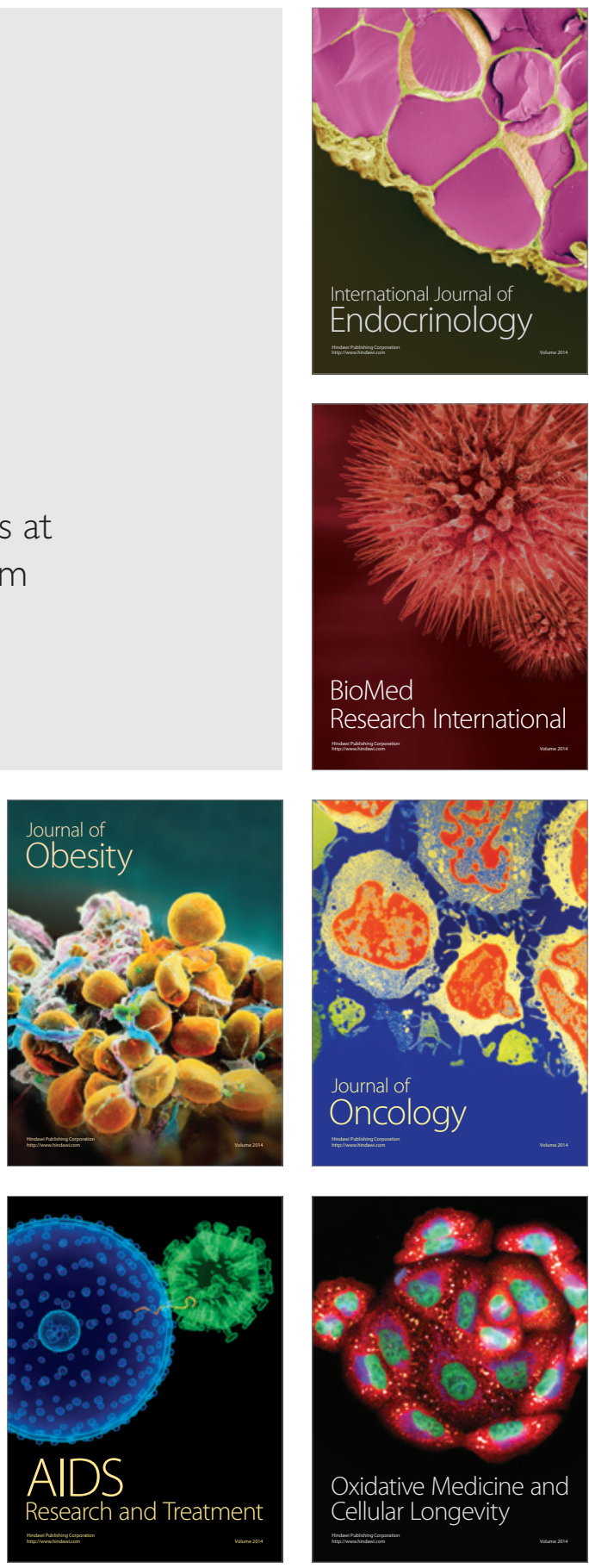